\title{
OPTIMIZATION OF INVENTORY ROUTING PROBLEM TO MINIMIZE CARBON DIOXIDE EMISSION
}

\author{
Balamurugan, T. ${ }^{* * *, \#}$; Karunamoorthy, L. ${ }^{* *}$; Arunkumar, N. ${ }^{*} \&$ Santhosh, D. \\ *Department of Mechanical Engineering, St. Joseph's College of Engineering, Chennai - 600119, \\ Tamilnadu, India \\ ** Department of Mechanical Engineering, College of Engineering, Guindy Campus, Anna University, \\ Chennai - 600025, Tamilnadu, India \\ E-Mail: balamurugant@ stjosephs.ac.in $\left({ }^{\#}\right.$ Corresponding author)
}

\begin{abstract}
This study proposes a modification in the considered two-stage inventory routing problem (IRP) to minimize the total amount of carbon dioxide $\left(\mathrm{CO}_{2}\right)$ emission in the network by reducing the total distance travelled by all the vehicles to meet the demand. Multiple suppliers (S) and multiple production units (PU's) are representing the two-stages of the IRP network. Each PU demand is fulfilled directly (single stage transportation) from the suppliers using homogeneous vehicles. This approach gives a long travel distance for every vehicle during each trip. The $\mathrm{CO}_{2}$ emission mainly depends on the distance travelled by the vehicle and vehicle characteristics. The proposed modification is the induction of Centralized collection and distribution centre (CCDC) between the suppliers and the PU's. It modifies the single stage transportation approach into a two-stage approach where $\mathrm{CO}_{2}$ emission is reduced due to less travel distance which is claimed as novelty in this study. An evolutionary algorithm of an artificial immune system (AIS) is used for studying both the network models with numerical data and their results are compared.

(Received in June 2017, accepted in November 2017. This paper was with the authors 2 weeks for 1 revision.)
\end{abstract}

Key Words: Inventory Routing, Homogeneous Vehicles, Carbon Dioxide Emission, Artificial Immune System

\section{INTRODUCTION}

The increasing amount of toxic gases like carbon dioxide $\left(\mathrm{CO}_{2}\right)$, carbon mono oxide and many greenhouse gases in the environment are responsible for global warming effect which is becoming a major critical threat on earth resulting in climatic changes in the world. Many governments and researchers have begun to pay close attention to green logistic concepts to reduce carbon dioxide emission caused by transportation. Though supply chain activities that include production, transportation and inventory emit $\mathrm{CO}_{2}$, transportation module gets the main attention due to larger $\mathrm{CO}_{2}$ emission [1]. In this direction, companies are inclined to adopt efficient vehicles such as electric and hybrid vehicles or to optimize their operational decisions. The latter one might be more economical in greater reduction of $\mathrm{CO}_{2}$ emission than employing low-energy-consuming technologies [2].

In this research, the considered IRP network is a two stage supply chain model contains multiple suppliers (vendors) and multiple PU's (customer or buyer). The demand of the individual PU is satisfied directly by the entire suppliers using homogeneous vehicles. This model is studied as the first scenario. The inclusion of a CCDC unit (Fig. 1) between multiple suppliers and multiple PU's forms the second scenario. This modification in the network is claimed as the novelty in this study. The second scenario is the modified IRP network contains three stages, namely multiple suppliers (vendors), CCDC unit and multiple PU's (customer or buyer). The suppliers of the above two models are having a unique set of the component mix with different lot sizes for each component is as shown in Table I. At the same time, certain components in the different component mix are common. Similarly, each production unit also requires a unique set of components as demand and certain components 
are common among the different Production unit (Table II). The demand of the CCDC unit for each individual component is obtained by adding the demand of all the production units. The function of CCDC is to procure the components for its cumulative demand from the suppliers and then, distribute to each production unit exactly according to their demand requirements. Homogeneous vehicles are used for the above process. Both models are evaluated to find the optimum vehicle route to meet the demands of production units which gives the minimum amount of $\mathrm{CO}_{2}$ emission based on the total travel distance.

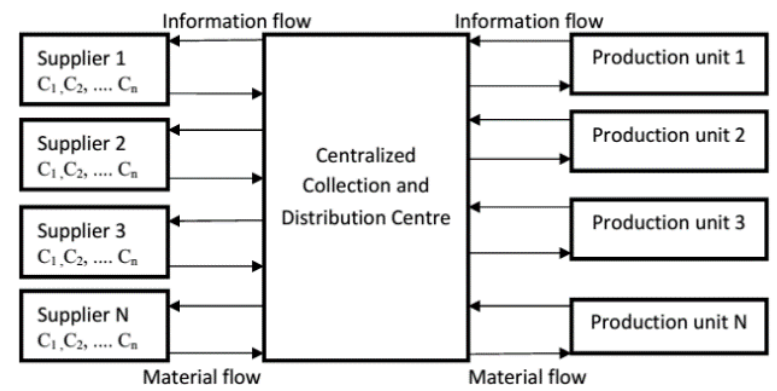

Figure 1: The proposed IRP network model with CCDC arrangement.

The IRP models were formally introduced by [3] and their recent complete academic reviews over the IRP systems were made by [4] followed by [5]. In the traditional IRP literature, researchers have considered only profits, costs and service levels through optimal inventory control strategy and vehicle schedules. Nowadays, the increase in environmental awareness related to transportation has drawn the attention of researchers and companies to consider fuel consumption or $\mathrm{CO}_{2}$ emissions to address the environmental issues in IRP models. To obtain the optimum vehicle schedules in the IRP models, the distance travelled by the each vehicle is considered as the main criterion. At the same time, $\mathrm{CO}_{2}$ emission is mainly based on the distance travelled by the vehicle and vehicle characteristics. So, distance is one of the key factors for the $\mathrm{CO}_{2}$ emission in a supply chain system. Hence the transportation plays a vital role in the network for $\mathrm{CO}_{2}$ emission. The network model considering transportation as the main source of $\mathrm{CO}_{2}$ emissions is given by [6] and a detailed review of the research in the green logistics can be found in [1,7].

The structure or topology of IRP models in literature [4] is classified into four types of networks, viz., One-to-One, One-to-Many, Many-to-One and Many-to-Many which decide the complexity of the problem.

In this research, the network of handling multi-product for many-to-many model is considered. The multi-product and multi-period logistics system [8] for one supplier with many customers under One-to-Many model is studied to reduce cost. Handling multi-products for many-to-many traditional IRP model, the decision support system is used for five different products to arrive the optimum transportation schedule for many plants to many destinations in a marine application [9]. A model for oil refineries to find the optimal route for the transportation of products using a fleet of ships [10] has proposed. The model of many-tomany have proposed by [11] where the product produced by one manufacturer (supplier) is not produced by any other manufacturer under a non-maritime approach to reduce the system's total cost by finding the optimum vehicle routing.

In the field of green supply chain, most of the literature deals with $\mathrm{CO}_{2}$ emission at the level of production processes or network design decisions. Similarly, studies considering environmental concern in IRP models are also limited. Different types of environmental constraints for a proposed production model [12] have studied to decide their optimal product mix and production quantities. A carbon cap policy is used [13] for choosing the transport mode. The efficiency of supply network pooling [14] is used in reducing $\mathrm{CO}_{2}$ emissions explained. A multi-product inventory model [15] has formulated for cold products with 
emission consideration. The network design decision models have studied [16-17] for environmental effects as $\mathrm{CO}_{2}$ emission is considered along with the cost reduction.

The significance of detailed transportation process analysis [18] have found in the reduction of costs and carbon emissions for an IRP model. To improve the performance in the IRP models to control greenhouse gas emissions using transshipment option [19] have proposed. An economic order quantity (EOQ) model [20] has formulated to integrate inventory management and truckload transportation with a carbon cap constraint.

However, the network deals multi-product under many-to-many model having unique product set at each supplier and customer along with the constraints such as lot size and number of lots has not been addressed in the traditional IRP as well the models of IRP considering $\mathrm{CO}_{2}$ emission problems so far to the best of our knowledge. So, there is a merit in the investigation of the proposed research under two different scenarios to evaluate and compare the amount of $\mathrm{CO}_{2}$ emission in the network from the optimum total distance travelled by all the vehicles using AIS algorithm.

To estimate the total amount of $\mathrm{CO}_{2}$ emission $\left(E_{T}\right)$ in the network, researchers employ basically two approaches to measure the greenhouse gas emissions for transportation operations. Use of emission or environmental impact factors obtained through other environmental studies is considered as one approach $[21,16]$. The other approach is based on the calculation of total energy consumed by the transportation operations. The first approach is used for this study to calculate the amount $\mathrm{CO}_{2}$ emission based on the average $\mathrm{CO}_{2}$ emission factor for Heavy Goods Vehicle (HGV) per km [22].

The AIS is already proved from its computational standpoint for the different applications, namely computer and network security [23], optimization problem [24], scheduling problems [25] and supply chain management [26].

The proposed model can be applied to the manufacturing as well as to the distribution industry such as the paper industry, automobile components, perishable items, groceries, cement and fuel. The rest of the paper is deliberated as follows: Section 2 describes the problem description, the model formulation and assumptions. Section 3 describes the AIS algorithm for Supply chain network. Section 4 describes the implementation of AIS with a numerical example. Section 5 indicates the results of the study. Section 6 concludes the study.

\section{PROBLEM DESCRIPTION}

This section describes the two-stage IRP network model under the two different scenarios as discussed earlier. Every supplier in the network is capable of supplying a unique set of components having a constriants such as lot sizes and number of lots as shown in Table I. Similarly, every production unit has a different component combination for the production as shown in Table II. The first scenario stands for many to many two-stage IRP model (Fig. 3) with suppliers and PU's. Here, the demand requirement of the individual production unit is satisfied directly (single stage transportation) by the entire suppliers in the network using homogeneous vehicles. Due to the constraint of lot size at the supplier, excess components will be retained as inventory at each PU. In the direct transportation approach, each vehicle has to visit every supplier to satisfy the demand of each PU that causes the high $\mathrm{CO}_{2}$ emission due to more transportation distance by all the vehicles. In order to reduce $\mathrm{CO}_{2}$ emission, the above network is modified as three stage supply chain model. It stands for the second scenario that consists of three main components, namely suppliers, CCDC and PU's, as shown in Fig. 1. Because of the addition of CCDC in the network, the considered network problem of many to many model is split into two sub problems, namely many to one and one to many model. The position of CCDC is apparently at the centre of PU's and the suppliers' location and their distances in the network are as shown in Fig. 2. The function of CCDC is to collect 
components from the suppliers and distribute them from CCDC to PU's. So, the CCDC obtains the details of the total demand of the individual components from the PU's for the procurement of components from the supplier to CCDC. After the collection of components from the supplier, CCDC will distribute the exact quantity of components to production unit based on their demand requirements. Here, the excess components will be retained as inventory at the CCDC because CCDC cannot procure the exact quantity of the required components from the supplier due to lot size as a constraint. Inventory for both the models will be utilized by the next period demand. Homogenous vehicles are used for the transportation of components in the network. Due to this modification in the network, the vehicles used for transportation provide less travel distance to satisfy the demand of all the production unit. The network for both the scenarios subject to a comparative analysis in terms of the total amount of $\mathrm{CO}_{2}$ emission based on the total travel distance of the vehicles.

\subsection{Assumptions}

- The demands for the PU's are known to the CCDC.

- Homogeneous vehicles are used for the collection and distribution of components.

- The availability of vehicles is enough to handle all the delivery requirements.

- A vehicle can visit more than one supplier as well as more than one PU in a single trip.

- Every supplier in the network is capable of supplying more than one type of component with different lot sizes. Similarly, for every component more than one supplier is available in the system.

- The cost of the same type components from all the suppliers is same.

- For handling of different components at the supplier's end as well as in the production unit, different container sizes are used for packing the components. Containers vary only in width; whereas the length and height of the container remain unaltered so as to accommodate components of an individual lot.

- Vehicle dimensions are taken as, length $\times$ width $\times$ height $(435 \times 200 \times 100) \mathrm{cm}^{3}$. The space for complete packing of the vehicle for loading is $8,700,000 \mathrm{~cm}^{3}$; the orientation of vehicle length $(435 \mathrm{~cm})$ will be shared as the width of the containers (used for components packing which may vary according to the volume of the batch size of the components); the width of the vehicle $(200 \mathrm{~cm})$ is fixed as the length of the container and the height of the vehicle $(100 \mathrm{~cm})$ is fixed as the height of the container. So the volume of the container is always represented as follows: $200 \times$ $\times 100 \mathrm{~cm}^{3}$.

- Vehicle loading at the supplier is in the order of supplier sequence according to the demand of the CCDC subject to the availability of components with the supplier.

- Vehicle loading at the CCDC is in the sequential order of the production unit.

- Setup time for producing components as batches is negligible.

- Vehicle loading and unloading duration is negligible.

- Ordering cost, loading cost and unloading cost for each component at supplier and production unit is included in the fixed cost of every vehicle.

- Setup cost and maintenance cost of the CCDC unit are also included in the fixed cost of each vehicle.

- All the vehicle used for transportation starts from the CCDC only.

\subsection{Indices and parameters}

$i \quad-$ index for suppliers $(i=1, \ldots, I)$,

$j \quad-$ index for production units $(j=1, \ldots, J)$,

$k \quad-$ index for vehicles $(k=1, \ldots, K)$, 
$n \quad-$ index for component $(n=1, \ldots, N)$,

$x \quad-$ index for number of lots at supplier $\left(x=1, \ldots, q_{\text {in }}\right)$,

$S \quad$ - supplier,

$P \quad$ - production unit,

C - component,

$V_{c} \quad$ - volume of the component in $\mathrm{cm}^{3}$,

$V_{l} \quad-$ volume of the lot in $\mathrm{cm}^{3}$,

$W_{l} \quad$ - weight of the lot in $\mathrm{kg}$,

$D_{T} \quad$ - total travel distance in $\mathrm{km}$,

$E_{k} \quad$ - amount of $\mathrm{CO}_{2}$ emission for vehicle $k$,

$E_{T} \quad$ - total amount of $\mathrm{CO}_{2}$ emission in $\mathrm{kg}$,

$E_{A f} \quad$ average $\mathrm{CO}_{2}$ emission factor per $\mathrm{km}$,

$Q_{n j}^{P} \quad$ - demand of the $n^{\text {th }}$ component of $j^{\text {th }}$ production unit,

$Q_{n} \quad-$ total demand of the $n^{\text {th }}$ component at the CCDC,

$q_{\text {in }} \quad$ - number of lots available as inventory at the supplier $i$ for $n^{\text {th }}$ component,

$q_{i n x}-x^{\text {th }}$ lot at supplier $i$ for $n^{\text {th }}$ component,

$I W_{n} \quad-$ inventory at the CCDC for $n^{\text {th }}$ component,

$h_{n} \quad-$ inventory carrying cost for the $n^{\text {th }}$ component for one period,

$C W$ - container width in $\mathrm{cm}$,

$V L_{k}^{S} \quad$ - vehicle length utilized during loading of vehicle $k$ used for supplier,

$V L_{k}^{p} \quad$ - vehicle length utilized during loading of vehicle $k$ used for Production units,

$d_{k}^{S} \quad-$ distance travelled by vehicle $k$ used for supplier,

$d_{k}^{P} \quad-$ distance travelled by vehicle $k$ used for Production units,

$d_{k} \quad-$ distance travelled by vehicle $k$,

$y_{u}=1$ - binary variable which is equal to 1 if $V L_{k}^{S} \neq 0$, and 0 otherwise,

$y_{v}=1$ - binary variable which is equal to 1 if $V L_{k}^{p} \neq 0$, and 0 otherwise,

$d_{S[i], S[i+1]} \quad-$ distance between $i^{\text {th }}$ supplier and $i+1^{\text {th }}$ supplier,

$d_{S[j], S[j+1]} \quad-$ distance between $j^{\text {th }}$ production unit and $j+1^{\text {th }}$ production unit,

$d_{S[i], W} \quad-$ distance between $i^{\text {th }}$ supplier and CCDC unit,

$d_{S[j], W} \quad-$ distance between $j^{\text {th }}$ supplier and CCDC unit,

$d_{S[i], S[i+1]}=0 \quad-$ when vehicle $k$ not visiting $S[i+1]$ from $S[i]$,

$d_{S[j], S[j+1]}=0 \quad-$ when vehicle $k$ not visiting $S[j+1]$ from $S[j]$,

$d_{S[i+1], W}=d_{W, S[i]}-$ when vehicle $k$ not visiting $S[i+1]$ from $S[i]$,

$d_{S[j+1], W}=d_{W, S[j]}-$ when vehicle $k$ not visiting $S[j+1]$ from $S[j]$.

$$
\begin{gathered}
\text { Minimize } E_{T}=D_{T} \times E_{A f} \\
D_{T}=\sum_{K=1}^{K} d_{k}^{S}+\sum_{K=1}^{K} d_{k}^{P U} \\
\text { s.t } \quad V L_{k}^{S}=\sum_{i=1}^{I} \sum_{n=1}^{N} \sum_{x=1}^{q_{i n}} C W_{i n x}^{S} \times y_{u} \quad \forall k, \quad k=1,2, \ldots, K \\
d_{k}^{S}=\sum_{i=1}^{I} d_{w, S[i]}+d_{s[i], s[i+1]}+d_{s[i+1], w} \quad \forall k, V L_{k}^{S}, \quad k=1,2, \ldots, K \\
Q_{n}=\sum_{j=1}^{J} Q_{n j}^{P} \quad \forall n, \quad n=1,2, \ldots, N \\
I W_{n}=Q_{n}-\sum_{i=S[i]}^{I} \sum_{x=1}^{q_{i n}} q_{n i x} \quad \text { if } I W_{n}<0 \text { then } n=n+1 \quad \forall n, \quad n=1,2, \ldots, N \\
V L_{k}^{P}=\sum_{j=1}^{J} \sum_{n=1}^{n} C W_{j n}^{P} \times y_{v} \quad \forall k, \quad k=1,2, \ldots, K \\
d_{k}^{P}=\sum_{j=1}^{J} d_{w, s[j]}+d_{s[j], s[j+1]}+d_{s[j+1],[w]} \quad \forall k, V L_{K}^{P} \quad k=1,2, \ldots, K
\end{gathered}
$$




$$
V L_{k}^{S} \leq 435 \& V L_{k}^{P} \leq 435 \forall k, \quad k=1,2,3, \ldots, K
$$

The objective function of Eq. (1) is to find the minimum amount of $\mathrm{CO}_{2}$ emission for the network, Eq. (2) gives the sum of the total distance travelled by all the vehicles at supplier and production unit, Eqs. (3) and (7) give the total vehicle space utilization for each vehicle, Eqs. (4) and (8) give the total distance travelled by each vehicle, Eq. (5) gives the total demand of the individual component, Eq. (6) gives the inventory at the CCDC for each component, Eq. (9) stands for vehicle space constraint.

\section{PROPOSED AIS ALGORITHM FOR IRP NETWORK PROBLEM}

The AIS algorithm for solving the IRP model is presented below. The vehicle routing schedules stands for the path in which the vehicle has to be operated to satisfy the demand of the network. The possible vehicle routing schedules are represented by integer valued sequences with the corresponding prefix s or p as follows: $s 1 \mathrm{~s} 2 \mathrm{~s} 3 \mathrm{~s} 4 \mathrm{p} 1 \mathrm{p} 2 \mathrm{p} 3 \mathrm{p} 4$. The total number of elements in each string is equal to the sum of the number of suppliers and PU's. Therefore, the total number of combination strings is composed of the permutations of supplier multiplied by permutations of PU. Those strings are accepted as antibodies of the AIS. The algorithm provides solution by the evolution of these antibodies. The proposed algorithm is presented below:

Create a population of $A$ antibodies ( $A$ is the parameter of antibody population size):

For each generation do:

Decode the antibodies (sequences) in the antibody population

Determine the total travel distance (affinity) of antibodies

Calculate the selection probabilities (rate of cloning)

Cloning (generate copies of the antibodies)

Steps in the mutation process:

For each generated clone do:

Inverse mutation (generate a new string)

Decode the new string

Calculate the total travel distance of the new string

if the total travel distance (new string) < total travel distance (clone) then

clone $=$ new string

else,

clone $=$ clone:

do pair wise interchange mutation (generate a new string):

decode the new string:

Calculate the total travel distance of the new string:

If the total travel distance (new string) < total travel distance (clone) then clone $=$ new string:

else

clone $=$ clone:

antibody= clone:

Eliminate worst $\% \mathrm{~B}$ number of antibodies in the population:

(B is the parameter of the elimination ratio of antibodies)

(Create new antibodies at the same number (\% B of population)

Change the newly created ones with the eliminated ones:

While stopping criteria $=$ false .

else

Repeat

stop: 


\section{IMPLEMENTATION OF AIS ALGORITHM TO IRP MODEL}

\subsection{Software development}

The artificial immune system algorithm is implemented in $\mathrm{C}$ language on a personal computer Pentium (R) Dual-core T4200@2.00 GHz with 2 GB RAM. The maximum number of iterations has been set to $25 \times N$, where $N$ is the population size.

\subsection{Numerical example}

The modified IRP network having CCDC model (scenario 2) is considered for the numerical illustration with the following data. Number of suppliers $=4$; number of production units $=4$; population size $(N)=5$; the vehicle model of TATA $909 \mathrm{EX}$ is considered for transportation model whose load carrying capacity is $6350 \mathrm{~kg}$ and its dimensions are taken as length $\times$ width $\times$ height $(435 \times 200 \times 100) \mathrm{cm}^{3}$. The suppliers and production unit details are shown in Table I and II. The schematic representation of the two models along with their distances to be evaluated using AIS are shown in Figs. 2 and 3. The evaluation of both models is carried out to find the minimum total amount of $\mathrm{CO}_{2}$ emission $\left(E_{T}\right)$ by all the vehicles and compared to the objective function. Defra [23] has reported the average emission factor for different type of vehicle at different loads. Here, the HGV model with average emission factor per $\mathrm{km}$ of $584.4 \mathrm{~g}$ is considered in the calculation of the amount of $\mathrm{CO}_{2}$ emission.

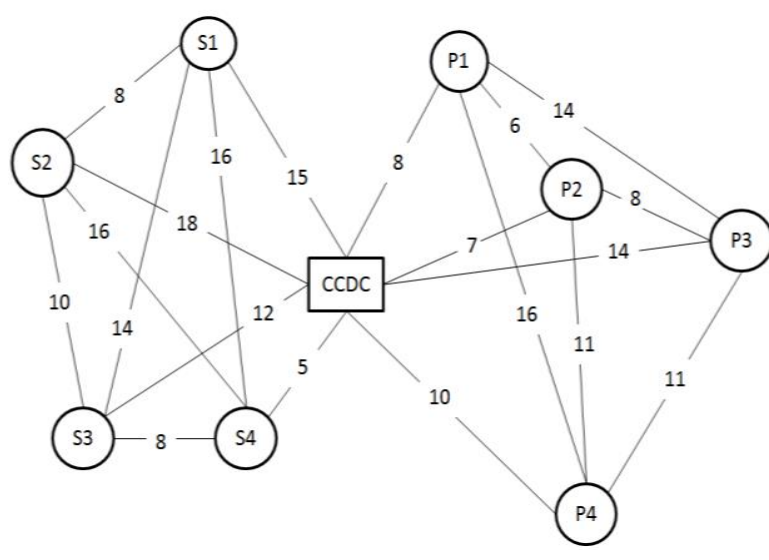

Figure 2: Proposed network with CCDC and its distance between suppliers and PU's in $\mathrm{km}$.

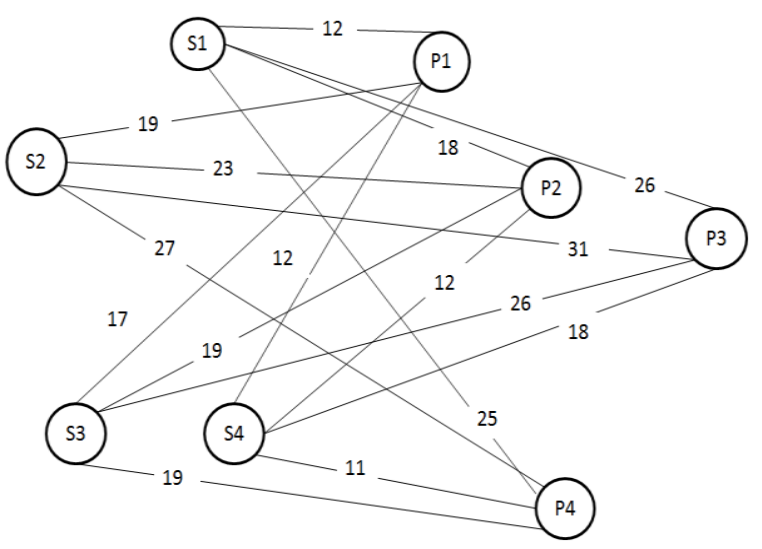

Figure 3: Two stage IRP network and its distance between supplier units and PU's in $\mathrm{km}$.

Vehicles are loaded with components using a container. Consider the supplier $S_{2}$ who can supply the component 1 with a lot size as 400 components requires $600000 \mathrm{~cm}^{3}$ spaces for packing. The width required to accommodate $600000 \mathrm{~cm}^{3}$ is calculated as $30 \mathrm{~cm}(600000 /$ $(200 \times 100)=30)$. So the container size is $200 \times \underline{\mathbf{3 0}} \times 100 \mathrm{~cm}^{3}$. The width of the container occupies $30 \mathrm{~cm}$ out of $435 \mathrm{~cm}$ of the vehicle length. Once the summation of the loaded container width exceeds $435 \mathrm{~cm}$, the vehicle will be sent for delivery and a new vehicle will arrive for loading. The width required for various containers are given in the last column of Table I and II.

Table I shows the details of the component mix for each supplier unit with its individual component lot size, the available number of lots, volume per lot and container width for each lot. 
Balamurugan, Karunamoorthy, Arunkumar, Santhosh: Optimization of Inventory Routing ...

Table I: Details of component for each supplier unit.

\begin{tabular}{|c|c|c|c|c|c|c|c|c|}
\hline$S$ & $C$ & Lot size & $q_{\text {in }}$ & $\begin{array}{c}h_{n} \\
\text { INR } \\
\end{array}$ & $\begin{array}{c}V_{c} \\
\left(\mathrm{~cm}^{3}\right)\end{array}$ & $\begin{array}{c}V_{l} \\
\left(\mathrm{~cm}^{3}\right)\end{array}$ & $\begin{array}{c}W_{l} \\
(\mathrm{~kg})\end{array}$ & $\begin{array}{r}C W \\
\left(\mathrm{~cm}^{3}\right)\end{array}$ \\
\hline \multirow{7}{*}{$S_{1}$} & 1 & 300 & 2 & 1.50 & 1500 & 450000 & 282 & 25 \\
\hline & 2 & 500 & 1 & 1.50 & 1500 & 750000 & 471 & 40 \\
\hline & 3 & 200 & 3 & 1.60 & 1531.25 & 306250 & 193 & 18 \\
\hline & 5 & 1000 & 2 & 0.75 & 750 & 750000 & 471 & 40 \\
\hline & 6 & 1500 & 2 & 0.75 & 625 & 937500 & 589 & 50 \\
\hline & 7 & 300 & 3 & 2.25 & 1875 & 562500 & 353 & 30 \\
\hline & 12 & 3000 & 2 & 0.25 & 123.16 & 369480 & 231 & 20 \\
\hline \multirow{8}{*}{$S_{2}$} & 1 & 400 & 2 & 1.50 & 1500 & 600000 & 377 & 30 \\
\hline & 3 & 400 & 2 & 1.60 & 1531.25 & 612500 & 384 & 35 \\
\hline & 4 & 500 & 2 & 2.00 & 1562.5 & 781250 & 490 & 40 \\
\hline & 5 & 1500 & 2 & 0.75 & 750 & 1125000 & 706 & 60 \\
\hline & 6 & 1500 & 4 & 0.75 & 625 & 937500 & 589 & 50 \\
\hline & 8 & 350 & 2 & 3.00 & 3000 & 1050000 & 659 & 55 \\
\hline & 9 & 400 & 3 & 1.25 & 1250 & 500000 & 314 & 25 \\
\hline & 11 & 300 & 4 & 3.00 & 3000 & 900000 & 565 & 50 \\
\hline \multirow{7}{*}{$S_{3}$} & 2 & 300 & 3 & 1.50 & 1500 & 450000 & 282 & 25 \\
\hline & 4 & 400 & 2 & 2.00 & 1562.5 & 625000 & 392 & 35 \\
\hline & 5 & 1000 & 3 & 0.75 & 750 & 750000 & 471 & 40 \\
\hline & 6 & 1000 & 3 & 0.75 & 625 & 625000 & 392 & 35 \\
\hline & 8 & 400 & 2 & 3.00 & 3000 & 1200000 & 753 & 60 \\
\hline & 9 & 200 & 5 & 1.25 & 1250 & 250000 & 157 & 15 \\
\hline & 10 & 500 & 3 & 1.00 & 1125 & 562500 & 353 & 30 \\
\hline \multirow{6}{*}{$S_{4}$} & 5 & 1500 & 3 & 0.75 & 750 & 1125000 & 706 & 60 \\
\hline & 6 & 2000 & 4 & 0.75 & 625 & 1250000 & 785 & 65 \\
\hline & 7 & 400 & 3 & 2.25 & 1875 & 750000 & 471 & 40 \\
\hline & 10 & 400 & 5 & 1.00 & 1125 & 450000 & 282 & 25 \\
\hline & 11 & 200 & 4 & 3.00 & 3000 & 600000 & 377 & 30 \\
\hline & 12 & 4500 & 2 & 0.25 & 123.16 & 554220 & 346 & 30 \\
\hline
\end{tabular}

Table II shows the details of the component mix for each production unit with its individual component demand size, volume and container width.

Table II: Demand details of the components of each production unit.

\begin{tabular}{|c|c|c|c|c|c|c|c|}
\hline $\boldsymbol{P}$ & $\boldsymbol{C}$ & $\boldsymbol{Q}$ & $\begin{array}{c}\boldsymbol{h}_{\boldsymbol{n}} \\
\mathbf{I N R}\end{array}$ & $\begin{array}{c}\boldsymbol{V}_{\boldsymbol{c}} \\
\left(\mathrm{cm}^{3}\right)\end{array}$ & $\begin{array}{c}\boldsymbol{V}_{\boldsymbol{l}} \\
\left(\mathrm{cm}^{3}\right)\end{array}$ & $\begin{array}{c}\boldsymbol{W}_{\boldsymbol{l}} \\
(\mathrm{kg})\end{array}$ & $\begin{array}{c}\boldsymbol{C W} \\
\left(\mathrm{cm}^{3}\right)\end{array}$ \\
\hline \multirow{6}{*}{$P_{1}$} & 1 & 500 & 1.50 & 1500 & 750000 & 471 & 40 \\
\cline { 2 - 8 } & 2 & 500 & 1.50 & 1500 & 750000 & 471 & 40 \\
\cline { 2 - 8 } & 3 & 500 & 1.60 & 1531.25 & 765625 & 481 & 40 \\
\cline { 2 - 8 } & 4 & 500 & 2.00 & 1562.5 & 781250 & 490 & 40 \\
\cline { 2 - 8 } & 5 & 2500 & 0.75 & 750 & 1875000 & 1177 & 95 \\
\hline & 6 & 2500 & 0.75 & 625 & 1562500 & 981 & 80 \\
\hline \multirow{4}{*}{$P_{2}$} & 12 & 1500 & 0.25 & 123.16 & 183985 & 116 & 10 \\
\cline { 2 - 8 } & 1 & 400 & 1.50 & 1500 & 600000 & 377 & 30 \\
\cline { 2 - 8 } & 3 & 400 & 1.60 & 1531.25 & 612500 & 384 & 35 \\
\cline { 2 - 8 } & 4 & 400 & 2.00 & 1562.5 & 625000 & 392 & 35 \\
\cline { 2 - 8 } & 6 & 2000 & 0.75 & 750 & 1500000 & 942 & 75 \\
\hline & 7 & 4000 & 0.75 & 625 & 1250000 & 785 & 63 \\
\hline & 9 & 400 & 2.25 & 1875 & 750000 & 471 & 38 \\
\cline { 2 - 8 } & 10 & 400 & 1.25 & 1250 & 500000 & 314 & 25 \\
\hline
\end{tabular}




\begin{tabular}{|c|c|c|c|c|c|c|c|}
\hline \multirow{5}{*}{$P_{3}$} & 2 & 600 & 1.50 & 1500 & 900000 & 565 & 45 \\
\cline { 2 - 8 } & 5 & 3000 & 0.75 & 750 & 2250000 & 1413 & 115 \\
\cline { 2 - 8 } & 6 & 3000 & 0.75 & 625 & 1875000 & 1177 & 95 \\
\cline { 2 - 8 } & 8 & 600 & 3.00 & 3000 & 1800000 & 1130 & 90 \\
\cline { 2 - 8 } & 9 & 600 & 1.25 & 1250 & 750000 & 471 & 40 \\
\cline { 2 - 8 } & 10 & 600 & 1.00 & 1125 & 675000 & 424 & 35 \\
\hline & 11 & 600 & 3.00 & 3000 & 1800000 & 1130 & 90 \\
\hline & 12 & 2400 & 0.25 & 123.16 & 294375 & 185 & 15 \\
\hline \multirow{5}{*}{$P_{4}$} & 4 & 500 & 2.00 & 1562.5 & 781250 & 490 & 40 \\
\hline & 5 & 2500 & 0.75 & 750 & 1875000 & 1177 & 95 \\
\cline { 2 - 8 } & 6 & 2500 & 0.75 & 625 & 1562500 & 981 & 80 \\
\cline { 2 - 8 } & 7 & 500 & 2.25 & 1875 & 937500 & 589 & 50 \\
\hline & 8 & 500 & 3.00 & 3000 & 1500000 & 942 & 75 \\
\cline { 2 - 8 } & 10 & 500 & 1.00 & 1125 & 562500 & 353 & 30 \\
\hline & 11 & 500 & 3.00 & 3000 & 1500000 & 942 & 80 \\
\hline & 12 & 2000 & 0.25 & 123.16 & 245313 & 154 & 15 \\
\hline \multirow{2}{*}{} & & & & & & & \\
\hline
\end{tabular}

Table III shows the randomly generated initial population set of sequences for the modified network (scenario 2) with its $E_{T}$ and $D_{T}$ values. The sequence with a less $E_{T}$ value among the set will have more clones. Affinity factor is calculated as $1 / E_{T}$.

Number of clones $=$ Round off [(affinity factor / total affinity factor $) \times$ population size] .

Table III: Initial population set of sequences with their $E_{T}, D_{T}$ values and number of clones.

\begin{tabular}{|c|c|c|c|c|c|c|c|c|c|c|c|c|c|}
\hline \multirow{2}{*}{$\begin{array}{l}\text { Seq. } \\
\text { no. }\end{array}$} & \multicolumn{8}{|c|}{ Generated sequence } & \multirow{3}{*}{$\begin{array}{c}\begin{array}{c}\boldsymbol{E}_{\boldsymbol{T}} \\
(\mathrm{kg})\end{array} \\
181.75\end{array}$} & \multirow{3}{*}{$\begin{array}{c}\begin{array}{c}D_{T} \\
(\mathrm{~km})\end{array} \\
311 \\
\end{array}$} & \multirow{3}{*}{$\begin{array}{c}\text { Affinity factor } \\
0.005502\end{array}$} & \multirow{3}{*}{$\begin{array}{c}\begin{array}{c}\text { Number of } \\
\text { clones }\end{array} \\
0.9347 \\
\end{array}$} & \multirow{3}{*}{$\begin{array}{c}\begin{array}{c}\text { Ceiled clone } \\
\text { value }\end{array} \\
1\end{array}$} \\
\hline & \multicolumn{4}{|c|}{$\mathbf{s}$} & \multicolumn{4}{|c|}{$\mathbf{p}$} & & & & & \\
\hline 1 & 2 & 1 & 3 & 4 & 4 & 1 & 2 & 3 & & & & & \\
\hline 2 & 2 & 4 & 3 & 1 & 3 & 2 & 1 & 4 & 171.23 & 293 & 0.005840 & 0.9921 & 1 \\
\hline 3 & 4 & 1 & 2 & 3 & 2 & 4 & 1 & 3 & 158.37 & 271 & 0.006314 & 1.0727 & 2 \\
\hline 4 & 1 & 2 & 4 & 3 & 2 & 3 & 4 & 1 & 175.90 & 301 & 0.005685 & 0.9658 & 1 \\
\hline 5 & 1 & 2 & 3 & 4 & 3 & 2 & 4 & 1 & 164.22 & 281 & 0.006089 & 1.0345 & 2 \\
\hline \multicolumn{11}{|c|}{ Total affinity factor } & 0.029430 & & \\
\hline
\end{tabular}

The sequences shown in the Table IV are sorted out in the ascending order on the basis of the $E_{T}$ and then repeated sequences are removed, followed by the removal of extra sequences above the population size at the bottom level. Finally, $30 \%$ of sequences (having higher total travel distance) from the bottom of the latest population set are replaced by newly generated random sequences as receptor editing process in order to give a new search space in the population set.

Table IV: Selected sequence after cloning and mutation process based on the $E_{T}$ value.

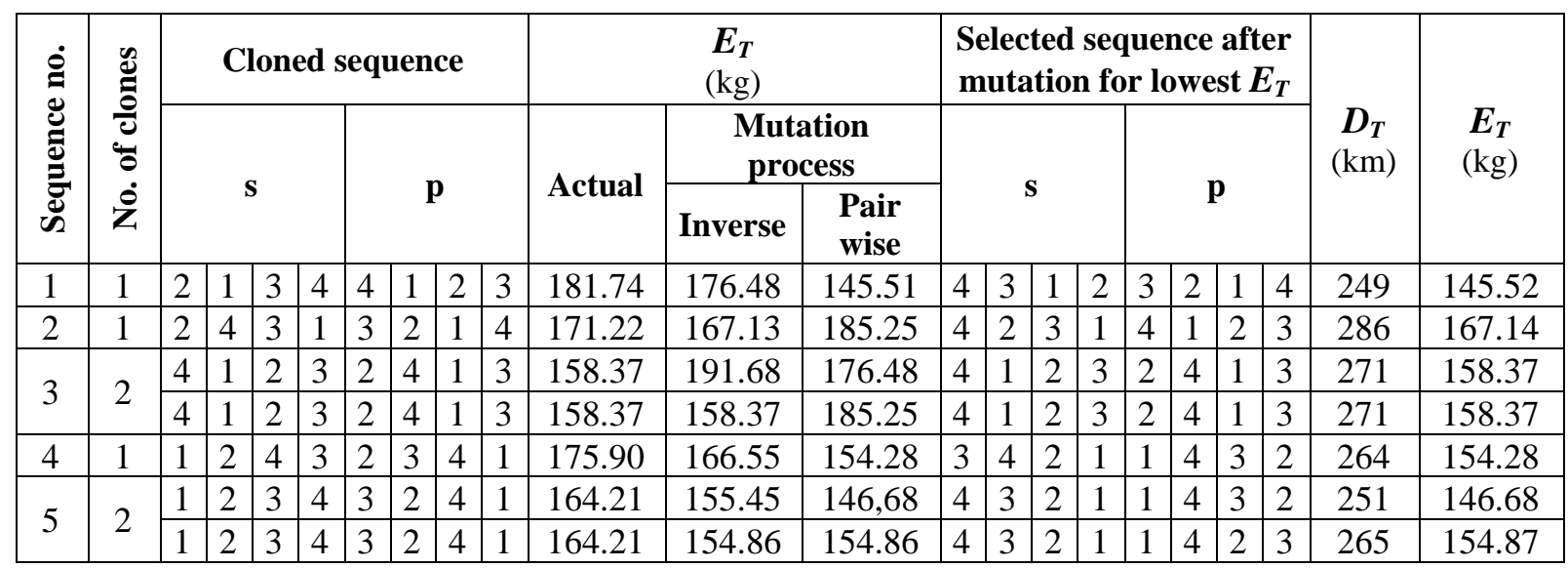


The above process gets terminated, if the top two antibodies of the previous iteration are same as that of current iteration antibodies obtained after the receptor editing process and the final result is obtained from the latest receptor editing process table. So the first antibody will give the minimum amount of $\mathrm{CO}_{2}$ emission with the total travel distance.

Table $\mathrm{V}$ shows the details of the optimum sequence with lowest $E_{T}$ and $D_{T}$ value along with each vehicle length utilization of the proposed network having CCDC (two-stage transportation) after the $9^{\text {th }}$ iteration of the simulation process.

Table V: Results of the antibody s-4 s-3 s-2 s-1 p-1 p-2 p-3 p-4 with their lowest $E_{T}$ and $D_{T}$ values.

\begin{tabular}{|c|c|c|c|c|c|c|c|}
\hline \multirow[b]{2}{*}{$\boldsymbol{K}$} & \multicolumn{3}{|c|}{ Suppliers - CCDC } & \multicolumn{4}{|c|}{ CCDC - Production units } \\
\hline & $\begin{array}{c}V L \\
200 \times--\times 100 \\
\left(\mathrm{~cm}^{3}\right)\end{array}$ & $\begin{array}{c}\boldsymbol{d}_{\boldsymbol{k}}^{S} \\
(\mathrm{~km})\end{array}$ & $\begin{array}{c}\boldsymbol{E}_{\boldsymbol{k}} \\
(\mathrm{kg})\end{array}$ & $\boldsymbol{K}$ & $\begin{array}{c}V L \\
200 \times \cdots 100 \\
\left(\mathrm{~cm}^{3}\right)\end{array}$ & $\begin{array}{c}\boldsymbol{d}_{\boldsymbol{k}}^{\boldsymbol{P}} \\
(\mathrm{km})\end{array}$ & $\begin{array}{c}\boldsymbol{E}_{\boldsymbol{k}} \\
(\mathrm{kg})\end{array}$ \\
\hline 1 & 375 & 10 & 5.84 & 1 & 410 & 21 & 12.27 \\
\hline 2 & 435 & 10 & 5.84 & 2 & 433 & 29 & 16.95 \\
\hline 3 & 425 & 25 & 14.61 & 3 & 405 & 35 & 20.45 \\
\hline 4 & 405 & 40 & 23.38 & 4 & 425 & 20 & 11.69 \\
\hline 5 & 248 & 41 & 23.96 & & & & \\
\hline & Total & 126 & 73.63 & & Total & 105 & 61.36 \\
\hline & $D_{T}=126+10$ & $231 \mathrm{kr}$ & & & $E_{T}=73.63+6$ & $=134$. & \\
\hline
\end{tabular}

Similarly, the two stage network also solved for the same input parameters using the same simulation procedure. Table VI shows the result of the network model without CCDC unit (direct transportation) is obtained after the $11^{\text {th }}$ iteration. The sequence shown in the table gives the lowest $E_{T}$ and $D_{T}$ values along with the vehicle length utilization for each vehicle.

Table VI: Results of the antibody p-1 p-4 p-2 p-3 s-2 s-1 s-3 s-4 with their lowest $E_{T}$ and $D_{T}$ values.

\begin{tabular}{|c|c|c|c|}
\hline $\boldsymbol{K}$ & $\begin{array}{c}\mathbf{2 0 0} \times \boldsymbol{\boldsymbol { L }} \\
\left(\mathrm{cm}^{3}\right)\end{array}$ & $\begin{array}{c}\boldsymbol{E}_{\boldsymbol{k}} \\
(\mathrm{kg})\end{array}$ & $\begin{array}{c}\boldsymbol{d}_{\boldsymbol{k}} \\
(\mathrm{km})\end{array}$ \\
\hline 01 & 430 & 23.38 & 40 \\
\hline 02 & 410 & 40.32 & 69 \\
\hline 03 & 431 & 50.25 & 86 \\
\hline 04 & 415 & 58.44 & 100 \\
\hline 05 & 430 & 38.57 & 66 \\
\hline \multicolumn{2}{|c}{ Total } & $E_{T}=210.96$ & $D_{T}=361$ \\
\hline
\end{tabular}

\section{RESULTS AND DISCUSSION}

The two-stage and its modified three-stage IRP networks are validated with different combinations of suppliers and PU's and their results are as shown in Table VII and VIII. In every combination, the scenario 1 follows direct (single stage) transportation approach and the scenario 2 uses the two-stage transportation approach. i.e., the method of satisfying the demand of the production units follows different approaches for the scenario 1 and scenario 2 . The input facts for solving the network scenarios are same for the given combination. Both scenarios are solved with the help of an AIS algorithm to find the optimum sequence which gives the minimum values for both $E_{T}$ and $D_{T}$.

The detailed discussion of the results of the network can be classified into two categories. First category stands for the network combination of equal number of supplier and PU's and second category stands for the network combination of different number of suppliers and PU's. In both categories, the result of the network clearly shows the advantages of CCDC in 
the IRP network being derived in terms of considerable reduction of $\mathrm{CO}_{2}$ emission due to a drastic cut in the total travel distance.

The results shown in Table VII compare the two scenarios of the network for different combinations which are standing for the first category where the number of suppliers and PU's are equal in the network. For each network combination, the value of $E_{T}$ and $D_{T}$ for scenario 2 is much lesser than the scenario 1 and its comparison and reduction of value in percentage with scenario 1 is shown in Table VII. The result of this category for each combination illustrates that, the scenario 2 shows an average reduction of $36.07 \%$ in the total $\mathrm{CO}_{2}$ emission $\left(E_{T}\right)$ as well as the total travel distance $\left(D_{T}\right)$ in comparison with the scenario 1 . This category gives an exemplary advantage of having a CCDC unit in the IRP network both in terms of $E_{T}$ and $D_{T}$ values.

Table VII: Result of the IRP model having equal number of PU's and suppliers in the network.

\begin{tabular}{|c|c|c|c|c|c|c|}
\hline $\begin{array}{l}\text { Network } \\
\text { combination }\end{array}$ & $\begin{array}{l}\text { Type of } \\
\text { network } \\
\text { scenario }\end{array}$ & Optimum sequence & $\begin{array}{c}\boldsymbol{E}_{\boldsymbol{T}} \\
(\mathrm{kg})\end{array}$ & $\begin{array}{c}\text { Reduction } \\
\text { on } \boldsymbol{E}_{\boldsymbol{T}} \\
((1-2) / 1) \\
\times 100(\%) \\
\end{array}$ & $\begin{array}{c}\boldsymbol{D}_{\boldsymbol{T}} \\
(\mathrm{km})\end{array}$ & $\begin{array}{c}\text { Reduction } \\
\text { on } \boldsymbol{D}_{\boldsymbol{T}} \\
((1-2) / 1) \\
\times 100(\%) \\
\end{array}$ \\
\hline \multirow{2}{*}{$\mathrm{p}-3 / \mathrm{s}-3$} & 1 & $\mathrm{p} 3 \mathrm{p} 2 \mathrm{p} 1 / \mathrm{s} 3 \mathrm{~s} 2 \mathrm{~s} 1$ & 133.82 & \multirow{2}{*}{34.91} & 229 & \multirow{2}{*}{34.91} \\
\hline & 2 & $\mathrm{~s} 1 \mathrm{~s} 2 \mathrm{~s} 3 / \mathrm{p} 3 \mathrm{p} 1 \mathrm{p} 2$ & 87.08 & & 149 & \\
\hline \multirow{2}{*}{$\mathrm{p}-4 / \mathrm{s}-4$} & 1 & $\mathrm{p} 1 \mathrm{p} 4 \mathrm{p} 2 \mathrm{p} 3 / \mathrm{s} 2 \mathrm{~s} 1 \mathrm{~s} 3 \mathrm{~s} 4$ & 210.96 & \multirow{2}{*}{36.01} & 361 & \multirow{2}{*}{36.01} \\
\hline & 2 & $\mathrm{~s} 4 \mathrm{~s} 3 \mathrm{~s} 2 \mathrm{~s} 1 / \mathrm{p} 1 \mathrm{p} 2 \mathrm{p} 3 \mathrm{p} 4$ & 134.99 & & 231 & \\
\hline \multirow{2}{*}{$\mathrm{p}-5 / \mathrm{s}-5$} & 1 & p1 p2 p3 p4 p5/ s2 s1 s4 s3 s5 & 241.35 & \multirow{2}{*}{37.28} & 413 & \multirow{2}{*}{37.28} \\
\hline & 2 & $\mathrm{~s} 2 \mathrm{~s} 1 \mathrm{~s} 4 \mathrm{~s} 3 \mathrm{~s} 5 / \mathrm{p} 1 \mathrm{p} 2 \mathrm{p} 4 \mathrm{p} 3 \mathrm{p} 5$ & 151.35 & & 259 & \\
\hline
\end{tabular}

The second category of analysis as shown in Table VIII is obtained with a variation in the number of production and supply units. If three production units are fulfilled by the four suppliers (P-3 / S-4) and vice versa forms the two network combination. For each network combination, the value of $E_{T}$ and $D_{T}$ for scenario 2 is much lesser than the scenario 1 and its comparison and reduction of value in percentage with scenario 1 is shown in Table VIII.

Based on the result, this category gives an average reduction of $13.11 \%$ for scenario 2 of $E_{T}$ and $D_{T}$ values over the scenario 1 . At the same time, the results of this category are much lesser (an average of $13.11 \%$ ) in comparison with the previous category (an average of $36.07 \%$ ) due to the reduction in the routing distance between the unequal number of supplier and PU's. Even though the second category as given in Table VIII alone is taken for consideration, there is an acknowledgeable and an appreciable role played by CCDC in the network models. The significant finding in the comparative study between these categories ascertains that the inclusion of CCDC in these network models gives environmental benefits through the reduction of the total $\mathrm{CO}_{2}$ emission $\left(E_{T}\right)$ in the network.

Table VIII: Result of the IRP model having different number of PU's and supplier in the network.

\begin{tabular}{|c|c|c|c|c|c|c|}
\hline $\begin{array}{c}\text { Network } \\
\text { combination }\end{array}$ & $\begin{array}{l}\text { Type of } \\
\text { network } \\
\text { scenario }\end{array}$ & Optimum sequence & $\begin{array}{c}\boldsymbol{E}_{\boldsymbol{T}} \\
(\mathrm{kg})\end{array}$ & $\begin{array}{c}\text { Reduction } \\
\text { on } \boldsymbol{E}_{\boldsymbol{T}} \\
((1-2) / 1) \\
\times 100(\%) \\
\end{array}$ & $\begin{array}{c}\boldsymbol{D}_{\boldsymbol{T}} \\
(\mathrm{km})\end{array}$ & $\begin{array}{c}\text { Reduction } \\
\text { on } \boldsymbol{D}_{\boldsymbol{T}} \\
((1-2) / 1) \\
\times 100(\%) \\
\end{array}$ \\
\hline \multirow{2}{*}{$\mathrm{p}-3 / \mathrm{s}-4$} & 1 & $\mathrm{p} 1 \mathrm{p} 3 \mathrm{p} 2 / \mathrm{s} 1 \mathrm{~s} 3 \mathrm{~s} 2 \mathrm{~s} 4$ & 147.27 & \multirow{2}{*}{14.68} & 252 & \multirow{2}{*}{14.68} \\
\hline & 2 & $\mathrm{~s} 1 \mathrm{~s} 4 \mathrm{~s} 3 \mathrm{~s} 2 / \mathrm{p} 3 \mathrm{p} 1 \mathrm{p} 2$ & 125.65 & & 215 & \\
\hline \multirow{2}{*}{$\mathrm{p}-4 / \mathrm{s}-3$} & 1 & $\mathrm{p} 4 \mathrm{p} 3 \mathrm{p} 1 \mathrm{p} 2 / \mathrm{s} 1 \mathrm{~s} 2 \mathrm{~s} 3$ & 182.33 & \multirow{2}{*}{11.53} & 312 & \multirow{2}{*}{11.53} \\
\hline & 2 & $\mathrm{~s} 1 \mathrm{~s} 2 \mathrm{~s} 3 / \mathrm{p} 1 \mathrm{p} 2 \mathrm{p} 3 \mathrm{p} 4$ & 161.29 & & 276 & \\
\hline
\end{tabular}




\section{CONCLUSION}

In the view of minimizing the total amount of $\mathrm{CO}_{2}$ emission in the considered two-stage IRP network, a modification of introducing a CCDC unit between the two stages of the network is proposed. This converts the network as the three-stage network. These two types of network approach have been solved for the various network combinations using an AIS algorithm to arrive the values of the optimum amount of the total $\mathrm{CO}_{2}$ emission in the network. From the results of these two approaches, the amount of reduction of the total $\mathrm{CO}_{2}$ emission in the modified network is calculated in comparison with the two-stage network. Based on the above comparison, the conclusions are drawn as follows:

(1) The included CCDC unit in the two-stage network reduces $\mathrm{CO}_{2}$ emission due to the reduced total travel distance travelled by all the vehicles to fulfil the demand of the network. This reduced travel distance in the network is because of the modified two-stage transportation approach instead of single- stage transportation approach.

(2) It is validated with different network combinations under two different categories. In both categories, the significance of the CCDC uint is proved through its calculated values, which is greatly less value than the values of the two-stage network.

From the above argument, It is proved that the inclusion of CCDC unit in the two-stage network under the given scenario is the more effective approach to reduce the total amount $\mathrm{CO}_{2}$ emission in the network through the reduced total travel distance covered by all the vehicles.

This proposed model is highly useful in manufacturing industries, retailer business and other VMI problems. The above problem has considered for a single period. So there is scope for studying the effect of this approach for more than one period with same demand or variable demand pattern to increase the environmental benefits by reducing $\mathrm{CO}_{2}$ emission in the IRP network.

\section{REFERENCES}

[1] Dekker, R.; Bloemhof, J.; Mallidis, I. (2012). Operations Research for green logistics - An overview of aspects, issues, contributions and challenges, European Journal of Operational Research, Vol. 219, No. 3, 671-679, doi:10.1016/j.ejor.2011.11.010

[2] Benjaafar, S.; Li, Y.; Daskin, M. (2013). Carbon footprint and the management of supply chains: insights from simple models, IEEE Transactions on Automation Science and Engineering, Vol. 10, No. 1, 99-116, doi:10.1109/TASE.2012.2203304

[3] Bell, W. J.; Dalberto, L. M.; Fisher, M. L.; Greenfield, A. J.; Jaikumar, R.; Kedia, P.; Mack, R. G.; Prutzman, P. J. (1983). Improving the distribution of industrial gases with an on-line computerized routing and scheduling optimizer, Interfaces, Vol. 13, No. 6, 4-23, doi:10.1287/inte.13.6.4

[4] Andersson, H.; Hoff, A.; Christiansen, M.; Hasle, G.; Løkketangen, A. (2010). Industrial aspects and literature survey: combined inventory management and routing, Computers \& Operations Research, Vol. 37, No. 9, 1515-1536, doi:10.1016/j.cor.2009.11.009

[5] Coelho. L. C.; Cordeau, J.-F.; Laporte, G. (2013). Thirty years of inventory routing, Transportation Science, Vol. 48, No. 1, 1-19, doi:10.1287/trsc.2013.0472

[6] Delgado, C.; Rosegrant, M.; Steinfeld, H.; Ehui, S.; Courbois, C. (1999). Livestock to 2020: the next food revolution, Food, Agriculture, and the Environment Discussion Paper 28, International Food Policy Research Institute, Washington, D.C., Food and Agriculture Organization of the United Nations, Rome, International Livestock Research Institute, Nairobi, 83 pages

[7] Seuring, S. (2013). A review of modeling approaches for sustainable supply chain management, Decision Support Systems, Vol. 54, No. 4, 1513-1520, doi:10.1016/j.dss.2012.05.053

[8] Xiao, N.; Rao, Y. L. (2016). Multi-product multi-period inventory routing optimization with time window constrains, International Journal of Simulation Modelling, Vol. 15, No. 2, 352-364, doi: $10.2507 / \mathrm{ijsimm} 15(2) \operatorname{co} 8$ 
[9] Bausch, D.; Brown, G. G.; Ronen, D. (1998). Scheduling short-term marine transport of bulk products, Maritime Policy \& Management, Vol. 25, No. 4, 335-348

[10] Persson, J. A.; Göthe-Lundgren, M. (2005). Shipment planning at oil refineries using column generation and valid inequalities, European Journal of Operational Research, Vol. 163, No. 3, 631-652, doi:10.1016/j.ejor.2004.02.008

[11] Ramkumar, N.; Subramanian, P.; Narendran, T. T.; Ganesh, K. (2012). Mixed integer linear programming model for multi-commodity multi-depot inventory routing problem, OPSEARCH, Vol. 49, No. 4, 413-429, doi:10.1007/s12597-012-0087-0

[12] Letmathe, P.; Balakrishnan, N. (2005). Environmental considerations on the optimal product mix, European Journal of Operational Research, Vol. 167, No. 2, 398-412, doi:10.1016/j.ejor. 2004.04.025

[13] Hoen, K. M. R.; Tan, T.; Fransoo, J. C.; Van Houtum, G. J. (2014). Effect of carbon emission regulations on transport mode selection under stochatic demand, Flexible Services and Manufacturing Journal, Vol. 26, No. 1-2, 170-195, doi:10.1007/s10696-012-9151-6

[14] Pan, S.; Ballot, E.; Fontane, F. (2013). The reduction of greenhouse gas emissions from freight transport by pooling supply chains, International Journal of Production Economics, Vol. 143, No. 1, 86-94, doi:10.1016/j.ijpe.2010.10.023

[15] Bozorgi, A. (2016). Multi-product inventory model for cold items with cost and emission consideration, International Journal of Production Economics, Vol. 176, 123-142, doi:10.1016/ j.ijpe.2016.03.011

[16] Wang, F.; Lai, X.; Shi, N. (2011). A multi-objective optimization for green supply chain network design, Decision Support Systems, Vol. 51, No. 2, 262-269, doi:10.1016/j.dss.2010.11.020

[17] Zhalechian, M.; Tavakkoli-Moghaddam, R.; Zahiri, B.; Mohammadi, M. (2016). Sustainable design of a closed-loop location-routing-inventory supply chain network under mixed uncertainty, Transportation Research Part E: Logistics and Transportation Review, Vol. 89, $182-$ 214, doi:10.1016/j.tre.2016.02.011

[18] Treitl, S.; Nolz, P. C.; Jammernegg, W. (2014). Incorporating environmental aspects in an inventory routing problem. A case study from the petrochemical industry, Flexible Services and Manufacturing Journal, Vol. 26, No. 1-2, 143-169, doi:10.1007/s10696-012-9158-Z

[19] Mirzapour Al-e-hashem, S. M. J.; Rekik ,Y.(2014). Multi-product multi-period inventory routing problem with a transshipment option: a green approach, International Journal of Production Economics, Vol. 157, 80-88, doi:10.1016/j.ijpe.2013.09.005

[20] Konur, D.(2014). Carbon constrained integrated inventory control and truckload transportation with heterogeneous freight trucks, International Journal of Production Economics, Vol. 153, 268-279, doi:10.1016/j.ijpe.2014.03.009

[21] Chaabane, A.; Ramudhin, A.; Paquet, M.; Benkaddour, M. A. (2008). An integrated logistics model for environmental conscious supply chain network design, Proceedings of the $14^{\text {th }}$ Americas Conference on Information Systems, Paper 175, 12 pages

[22] Defra (2011). 2011 Guidelines to Defra/DECC's GHG Conversion Factors for Company Reporting: Methodology Paper for Emission Factors, Technical Report, Department for Environment, Food and Rural Affairs, London

[23] Forrest, S.; Hofmeyr, S. (2001). Engineering an immune system, Graft, Vol. 4, No. 5, 5-9

[24] Trojanowski, K.; Wierzchon, S. T. (2002). Searching for memory in artificial immune system, Proceedings of the International Symposium on Intelligent Information Systems, 175-183

[25] Chandrasekaran, M.; Asokan, P.; Kumanan, S.; Balamurugan, T.; Nickolas, S. (2006). Solving job shop scheduling problems using artificial immune system, International Journal of Advanced Manufacturing Technology, Vol. 31, No. 5-6, 580-593, doi:10.1007/s00170-005-0226-3

[26] Kumar, V. N. S. A.; Kumar, V.; Brady, M.; Garza- Reyes, J. A.; Simpson, M. (2017). Resolving forward-reverse logistics multi-period model using evolutionary algorithms, International Journal of Production Economics, Vol. 183, Part B, 458-469, doi:10.1016/j.ijpe.2016.04.026 